\title{
Emar Maier On the exceptionality of reported speech
}

https://doi.org/10.1515/lingty-2019-0009

\section{Introduction}

Spronck and Nikitina (S\&N) have taken on the task of defining a linguistic phenomenon that has managed to elude definition, despite playing a key role in many subfields of linguistics. In formal semantics in particular, speech reports have been at the center of attention from the very beginning (Frege 1892). S\&N's endeavor presupposes that there is something worth defining, i.e. that reported speech is indeed a linguistic category of its own, not an arbitrary intersection of various other, larger linguistic categories such as clausal embedding and evidentiality. In this response I want to provide additional, semantic evidence for S\&N's claim that reported speech should be treated as a linguistic category.

\section{The traditional picture: Attitude ascription, quotation, and evidentiality}

As S\&N point out, the cluster of phenomena that they call reported speech is not always considered a linguistic category in its own right. In semantics, in particular, it is rather considered a mixture of (at least) three fundamentally distinct subtypes, viz. direct and indirect reported speech and reportative evidentials, each reducible to a larger category. Let me start by reviewing this traditional picture.

First, indirect reported speech is considered just a special case of the larger natural class of attitude ascriptions:

(1) Maria said/yelled/thought/believed/imagined/hoped that Sue stole her idea.

Syntactically these are all clausal complement constructions, and semantically they are analyzed as intensional operators, i.e. quantifiers over possible worlds:

Emar Maier [' eImar ' maırr], University of Groningen, Groningen, Netherlands, E-mail: emar.maier@gmail.com 
(1) is true iff Sue stole Maria's idea in all the possible worlds compatible with what she said/believed/etc. ${ }^{1}$

Second, direct reported speech is considered a special case of the larger natural class of quotations, which includes not only speech report uses of quotation marks, but also some thought reports (2b), and so-called pure quotation or mention (2c), perhaps even scare quotes, role shift, demonstration, etc.:
a. Maria said: "Sue stole my idea."
b. "Yeah right", she thought, "Good luck with that."
c. The word "thought" starts with a "th" and ends in " $h t$ ".

Semantically, what unifies the broad class of quotations is metalinguistic reference, i.e. reference to linguistic expressions.

Reportative evidentials, finally, are considered a species of evidential marking: ${ }^{2}$
a. Para-sha-n-mi.
b. Para-sha-n-si. rain-PROG-3-DIR rain-PROG-3-REP 'It is raining(, I see).' 'It is raining(, I'm told).'

(Cuzco Quechua, Faller 2002:3)

Semantically, the unifying characteristic of evidentiality is that it is a way of specifying what evidence one has for a specific claim, in a such a way that this evidence information is 'backgrounded'. In current terminology, the at-issue contribution of (3) is that it is raining, and the not-at-issue contribution is that the speaker has either direct perceptual or indirect hearsay evidence for this (Murray 2017).

Summing up, on the traditional picture there is no category of reported speech, but a cluster of distinct phenomena that can be used for various things, including but not limited to reporting what someone said. Yet, over the years various isolated semantic phenomena have been brought to light that seem to support S\&N's thesis that there really is something special about speech reports after all.

\footnotetext{
1 The notion of a world being compatible with what was said/believed/etc. can be further explicated in possible worlds theory. The locus classicus for the analysis of indirect speech as an intensional operator is Kaplan (1989).

2 Here and below I present Faller's glosses of Cuzco Quechua data, using her abbreviations for affixes and enclitics: $\mathrm{PROG}$ = progressive; 3 = third person; DIR = direct evidential; REP = reportative evidential; $\mathrm{PL}$ = plural; ILLA = illative; TOP = topic; $\mathrm{ACC}$ = accusative case; INCL = inclusive; LOC = locative case; $\mathrm{PP}$ = past participle; $\mathrm{ADD}$ = additive; 10 = first person object recipient; SURP = surprise; NEG = negative (Faller 2002:xiii-xiv).
} 


\section{The special status of speech reports}

I aim to establish that, within each of the traditional broad semantic categories reviewed above, the speech reporting subclasses tend to behave rather differently from the remainders.

\subsection{Speech vs. attitude: Closure issues}

Among attitude ascriptions, speech reports are known to exhibit some special behaviors. For instance, in some languages only speech reports will allow certain types of indexical shift (cf. Deal (2017) for a recent overview). I want to focus here on an aspect of the semantics of speech and attitude reports that has received far less attention.

On the intensional operator approach mentioned above, it follows that if $\mathrm{x}$ believes that $\varphi$, and $\varphi$ in fact entails $\psi$, then $\mathrm{x}$ believes that $\psi$. This prediction, known in the philosophical literature as 'closure under logical entailment' (or 'logical omniscience'), is illustrated by the pair in (4), where the first indeed intuitively entails the second.

(4) John believes that his best friends Sue and Mark both own fancy new electric bikes.

$\Rightarrow \quad$ John believes that at least one of his friends owns a bike.

Some consequences of this general pattern may be more problematic. In particular, since logical and mathematical truths are necessary (i.e. true in all possible worlds), it follows that John, or anyone else that is capable of believing anything, must believe that if it's raining it's raining, and also that 42589 is a centered triangular prime number - a result that perhaps makes some sense if we assume John to be an idealized hyperrational agent. In any case, as (4) shows, for attitudes like belief, knowledge, and imagination at least some degree of logical closure seems plausible.

For speech reporting, however, closure is extremely limited. Perhaps with the plain verb 'say' we can get readings where the first statement in (5) entails the second, ${ }^{3}$ but with the more descriptive communication verbs in (5) any entailments are off.

3 von Stechow \& Zimmermann (2005), in a footnote, suggest there may be an ambiguity in English indirect 'say' constructions, where one reading is closed under entailment, and the other requires more faithful reporting. See Brasoveanu \& Farkas (2007), Sæbø (2013) and Bary \& Maier (2018) for some further discussion. 
John said/yelled/muttered/whispered/claimed that his best friends Sue and Mark both own fancy new electric bikes.

$\nRightarrow$ John said/yelled/muttered/whispered/claimed that at least one of his friends owns a bike.

What's more, even the most hyperrational, idealized agent surely does not necessarily say that if it's raining it's raining, or that 42589 is a centered irregular prime - even if we accept that they (should) believe it in some weak or normative sense.

In sum, the traditional unified view of speech and attitude reports as intensional operators cannot do justice to the fact that speech reports are typically not closed under logical entailment, or at least to a lesser degree than belief- and imagination-like attitude reports. ${ }^{4}$ In other words, among indirect attitude ascriptions (or intensional clausal complement constructions), there really is something special about the logic of speech reports.

\subsection{Quotation and demonstration}

The traditional uniform semantics of quotation, broadly construed, starts from the idea that quotation marks turn an expression $\alpha$ into a name or other type of expression that refers to $\alpha$. Applied to direct speech reports, this means that 'say' expresses a relation between a subject and a linguistic expression: ' $x$ says " $\alpha$ "' is true iff $\mathrm{x}$ stands in this say-relation to the expression $\alpha$. Setting aside independent counterarguments involving ellipsis, anaphora, and mixed quotation (Maier 2014), a major obstacle for this neat semantic reduction of quotation phenomena to metalinguistic reference, is that in conversation we often quote more than just linguistic expressions. Colloquial quotative constructions bring this out most forcefully: ${ }^{5}$

(6) So Martha was like, Jeez <looks annoyed $>$, what uhh, what are you asking me $<$ points at chest $>$ for? <shakes head $>$

\footnotetext{
4 It has often been observed that for preferential attitudes (fear, hope, want), closure is likewise problematic: If Sue wants Mary and John to come to her party, it doesn't follow that she wants Mary to come (perhaps she only likes them as a couple) (Heim 1992). The argument from closure alone therefore doesn't suffice to isolate speech reports from the larger class of attitude reports. The literature provides various other inference patterns and other special properties of these preferential attitudes that set them apart from speech reports (see e.g. Anand \& Hacquard 2013). 5 S\&N take the incorporation of non-linguistic demonstrations on board in their definition of reported speech generally, as witness the 'semiotic status of demonstratedness' clause in their definition.
} 
This is a direct speech report, as witness the direct question and shifted indexicals (you and me pick out the reported addressee and speaker). But the reporter does more than just quote Martha's words, he's also ‘quoting' some of her gestures, facial expressions, and actions. ${ }^{6}$

Starting from colloquial data like this, Clark \& Gerrig (1990) propose that reported speech is not a subclass of metalinguistic quotation, but rather of a different phenomenon they call demonstration. In recent work I've tried to take the best of both worlds: the report part in a direct speech report like (6) is the reporter's demonstration of something Martha did, which must have consisted of, among other things, an utterance event (in speech, thought, or signs) with the specific linguistic form given by the quoted words (Maier 2017). For now, the important consequence of such an approach is that, again, speech reports are special: unlike pure quotations they naturally combine with non-linguistic gestures and other actions to form complex multi-modal reports/demonstrations, and unlike purely non-linguistic demonstrations (e.g. "No, no, more like < demonstrates a dance move> See?") they designate events that have a linguistic form.

\subsection{Evidentials and reportative exceptionality}

Although the exact definition of evidentiality is still a matter of some debate, there is a strong case to be made that in certain languages with rich evidential morphology, reportative evidentials are as much part of the evidential system as direct perception evidentials or inferential evidentials (Aikhenvald 2004). ${ }^{7}$ But, semantically speaking, there is something special about the reportative subtype, even in these languages with dedicated evidential morphological paradigms.

Typically, a speaker is committed to the propositions she asserts. You can't say 'It's raining' and then follow up with 'But it's not raining'. According to the standard conception of evidentiality reviewed above (and in line with the notion of 'evidentiality' in S\&N's proposed definition of speech reporting), the assertion of an evidential construction contributes two propositions, one at-issue ( $p$ ) and one not-at-issue (speaker has such-and-such evidence for $p$ ). We thus predict that the speaker will be committed to both propositions. Cross-linguistically, the

6 Such mixtures of quoted language and gesture abound in the sign language linguistics literature, giving rise to terminology like ‘constructed action' (Liddell \& Metzger 1998) and 'action role shift' (Schlenker 2017).

7 Not so much, perhaps, for so-called quotative evidentials (Bary \& Maier 2018). 
expected commitment to the at-issue (or 'scope') proposition is easily verified by the infelicity of statements like (7).

(7) \#Para-sha-n-mi, ichaqa mana crei-ni-chu rain-PROG-3-DIR but not believe-1-NEG 'It is raining (I see), but I don’t believe it.' (Cuzco Quechua, Faller 2002)

For reportative evidentials however there seems to be no commitment to the atissue proposition: ${ }^{8}$

(8) Pay-kuna-s ñoqa-man-qa qulqi-ta muntu-ntin-pi saqiy-wa-n, mana-má (s)he-PL-REP I-ILLA-TOP money-acc lot-INCL-LOC leave-1O-3 not-SURP riki riku-sqa-ykini un sol-ta centavo-ta-pis saqi-sha-wa-n-chu right see-PP-2 not one Sol-ACC cent-ACC-ADD leave-PROG-10-3-NEG 'They left me a lot of money (I was told), but, as you have seen, they didn't leave me one sol, not one cent.' (Cuzco Quechua, Faller 2002)

The contrast in at-issue-content-commitment between reportative and other types of evidentials seems to be so crosslinguistically robust ${ }^{9}$ that AnderBois (2014) refers to it as 'reportative exceptionality'. In short, there is strong evidence that within evidential systems, speech reports have a special status.

\section{A note about narrative perspective shifts}

I end with a brief, more speculative note about Free Indirect Discourse (FID) and perspective shift in narrative. FID is a way of describing a character's thoughts and utterances in a way that combines features of both direct and indirect discourse (Banfield 1982).

(9) She stared at her computer. Oh no, the deadline was tomorrow! How on earth was she going to finish the paper before then?

Within semantics there has been considerable interest in this phenomenon (Schlenker 2004; Maier 2015; Eckardt 2014). One popular analysis emerging from this debate starts from the idea that these sentences are to be evaluated with respect to two 'perspectives', i.e. formally, two distinct context parameters: the

8 Indeed, S\&N take this lack of commitment to the reported content component as one of the defining characteristics of speech reports ('modality').

9 One exception AnderBois notes is St'át'imcets, where speakers do seem to be committed to the at-issue contribution in a reportative evidential construction (Matthewson et al. 2007). 
context of narration and the protagonist's context of thought. More recently, this 'bicontextual' approach has been extended to deal with other kinds of perspective shifts, such as 'Protagonist Projection', (10a), and 'Viewpoint Shift', (10b).

a. He gave her a ring studded with diamonds but they turned out to be glass. (Holton 1997)

b. The T-Rex hesitated. Maybe the little dinosaurs had hidden themselves in the cave on his left. When Billy looked up in his hiding place a few seconds later, a T-Rex bent down to the entrance of the cave and squinted into the dark. (Hinterwimmer 2017)

The idea is that in (10a) the ring is studded with diamonds from the perspective of the woman receiving the ring, but it's glass from the narrator's perspective. In (10b) the T-Rex is familiar from the perspective of the narrator and the reader, hence the definite article in the first sentence, but unfamiliar from the perspective of the little dinosaur character Billy, hence the indefinite article in the third sentence.

While Stokke (2013) and Abrusán (2018) stress the similarities between the phenomena in (9) and (10) - with Abrusán even hinting at a continuum of perspective shifting -, Hinterwimmer stresses the differences. He describes three linguistic tests to tease apart FID and Viewpoint Shift. For example, while FID is a root phenomenon, Viewpoint Shift may occur in embedded positions. In fact, decades earlier, Banfield (1982) had likewise proposed linguistic tests for distinguishing FID from a type of narrative perspectival shift that she called 'the representation of non-reflective consciousness'. For example, Banfield shows that adding expressive elements like exclamations or vocatives turn a perspective shift into a full-fledged FID report (again in line with S\&N's 'demonstratedness' criterion for reported speech). ${ }^{10}$

The picture that emerges from the Banfield/Hinterwimmer observations is one where FID is a quotation-like type of speech reporting (where speech includes inner speech, i.e. thought), while Viewpoint Shift (and presumably at least some examples of Protagonist Projection) is a way of describing a character's perceptual sensations or other non-linguistic, non-reflective mental states. In other words, within the broad class of perspective shift phenomena, the reportative variety known as FID stands out as a separate phenomenon with its own quotation-like syntax and semantics.

10 Interestingly, Vandelanotte (2009), who argues explicitly against Banfield's analysis in terms of non-reflective consciousness, still agrees with the general observation I'm highlighting here, viz. that some cases of apparent perspective shifting (e.g. in what he calls narrated perception) are not FID, despite superficial similarities. 


\section{Conclusion}

Looking over the formal semantics literature on reported speech constructions, I find myself in agreement with much of what S\&N conclude from their typological studies. On future occasions we could quibble over the details of the proposed definition - Do cases of standard indirect discourse or hearsay evidentiality really always involve 'demonstratedness'? And in what sense does a free indirect speech or thought representation in a fictional narrative mark 'evidentiality' or 'source of information'? But in this commentary I've restricted myself to providing support for S\&N's general project from a semanticist's perspective. More specifically I've listed a number of ways in which speech reports differ semantically from various related phenomena to which they have been reduced by other semanticists. My hope is that these observations may prove helpful in the emancipation of speech reports as a dedicated linguistic category.

Acknowledgment: This research is supported by NWO Vidi Grant 276-80-004 (FICTION).

\section{References}

Abrusán, Márta. 2018. Protagonist projection. Presentation at SALT 28, MIT, May 2018. https://salt28mit.files.wordpress.com/2018/05/abrusansalt.pdf

Aikhenvald, Alexandra. 2004. Evidentiality. Oxford: OUP.

Anand, Pranav \& Valentine Hacquard. 2013. Epistemics and attitudes. Semantics and Pragmatics 6. doi:10.3765/sp.6.8.

AnderBois, Scott. 2014. On the exceptional status of reportative evidentials. In Proceedings of SALT 24. 234-254.

Banfield, Ann. 1982. Unspeakable sentences: Narration and representation in the language of fiction. London: Routledge \& Kegan Paul.

Bary, Corien \& Emar Maier. 2018. The landscape of speech reporting. Ms. Nijmegen/Groningen. https://ling.auf.net/lingbuzz/003526.

Brasoveanu, Adrian \& Donka Farkas. 2007. Say reports, assertion events and meaning dimensions. Pitar Mos: A building with a view. Papers in honour of Alexandra Cornilescu 175-196.

Clark, Herbert \& Richard Gerrig. 1990. Quotations as demonstrations. Language 66(4). 764-805.

Deal, Amy Rose. 2017. Shifty asymmetries: Universals and variation in shifty indexicality Ms. Berkeley. http://linguistics.berkeley.edu/ ardeal/papers/Deal-indexicals-2017.pdf.

Eckardt, Regine. 2014. The semantics of Free Indirect Speech. How texts let you read minds and eavesdrop. Leiden: Brill.

Faller, Martina T. 2002. Semantics and Pragmatics of evidentials in Cuzco Quechua: Stanford dissertation. http://personalpages.manchester.ac.uk/staff/martina.t.faller/documents/ Thesis-A4.pdf. 
Frege, Gottlob. 1892. Über Sinn und Bedeutung. Zeitschrift für Philosophie und Philosophische Kritik 100(1). 25-50.

Heim, Irene. 1992. Presupposition projection and the semantics of attitude verbs. Journal of Semantics 9(3). 183-221.

Hinterwimmer, Stefan. 2017. Two kinds of perspective taking in narrative texts. Proceedings of SALT 27. 282-301. doi:10.3765/salt.v27i0.4153.

Holton, Richard. 1997. Some telling examples: A reply to Tsohatzidis. Journal of Pragmatics 28. 625-628.

Kaplan, David. 1989. Demonstratives. In Joseph Almog, John Perry \& Howard Wettstein (eds.), Themes from Kaplan, 481-614. New York: Oxford University Press.

Liddell, Scott \& Melanie Metzger. 1998. Gesture in sign language discourse. Journal of Pragmatics 30(6). 657-697. doi:10.1016/S0378-2166(98)00061-7.

Maier, Emar. 2014. Mixed quotation: The grammar of apparently transparent opacity. Semantics and Pragmatics 7(7). 1-67. doi:10.3765/sp.7.7.

Maier, Emar. 2015. Quotation and unquotation in free indirect discourse. Mind and Language 30(3). 235-273. doi:10.1111/mila.12083.

Maier, Emar. 2017. The pragmatics of attraction: Explaining unquotation in direct and free indirect discourse. In Paul Saka \& Michael Johnson (eds.), The semantics and pragmatics of quotation. Berlin: Springer. http://ling.auf.net/lingbuzz/002966.

Matthewson, Lisa, Henry Davis \& Hotze Rullmann. 2007. Evidentials as epistemic modals: Evidence from St'át'imcets. Linguistic variation yearbook 7(1). 201-254.

Murray, Sarah E. 2017. The semantics of evidentials. Oxford: Oxford University Press.

Sæbø, Kjell Johan. 2013. Reports of specific indefinites. Journal of Semantics 30(3). 267-314. doi:10.1093/jos/ffs015.

Schlenker, Philippe. 2004. Context of thought and context of utterance: A note on Free Indirect Discourse and the Historical Present. Mind and Language 19(3). 279-304. doi:10.1111/j.1468-0017.2004.00259.x.

Schlenker, Philippe. 2017. Super Monsters I: Attitude and action role shift in sign language. Semantics and Pragmatics 10(9). doi:10.3765/sp.10.9.

Stokke, Andreas. 2013. Protagonist projection. Mind and Language 28(2). 204-232. doi:10.1111/mila.12016.

Vandelanotte, Lieven. 2009. Speech and thought representation in English. A cognitive-functional approach. Berlin: Mouton.

von Stechow, Arnim \& Ede Zimmermann. 2005. A problem for a compositional treatment of de re attitudes. In Greg Carlson \& Francis Pelletier (eds.), Reference and quantification: The Partee effect, 207-228. Stanford: CSLI. 